\title{
Futebol e comunicação, um processo de consumo chamado paixão*
}

\author{
Soccer and communication, a consumption \\ process called passion
}

\author{
Fútbol y comuniceación, un proceso \\ de consumo llamado pasión
}

\section{Rafael Prieto Ferraz}

- Bacharel em Comunicação Social - Publicidade e Propaganda pela Escola de Comunicações e Artes da Universidade de São Paulo (ECA-USP)

- Supervisor de Planejamento Estratégico na agência de propaganda Lew'Lara|TBWA

- Editor de conteúdo do site do Grupo de Planejamento de Marca e Comunicação do Brasil

- Atuou no planejamento estratégico das agências BorghiErh/Lowe e JWT

- Apresentou um paper na divisão temática "Interfaces comunicacionais", no XXXIV Congresso Brasileiro de Ciências da Comunicação - Recife, em setembro de 2011

-prietoferraz@gmail.com

* Este artigo foi escrito sob a orientação do Prof. Dr. Leandro Leonardo Batista e a co-orientação do Prof. Arthur Meucci. 
Os clubes futebolísticos, além de exercer papel identitário, são capazes de apresentar forte poder aglutinador sobre as pessoas, as quais podem manifestar o sentimento de pertencimento a esse grupo pelo consumo simbólico do clube e/ ou de seus produtos e serviços. A comunicação, além de financiar e hiperbolizar o espetáculo esportivo, se constitui em ferramenta ratificadora das identidades clubísticas como forma de potencializar esse processo de consumo.

PALAVRAS-CHAVE: ESPORTE • COMUNICAÇÃO • FUTEBOL • CONSUMO • PROPAGANDA

\section{Abstract}

The soccer teams, besides exercising an identity role, can generate a powerful social bond among people, which can also manifest the people's feeling of belonging through the symbolic consumption of the team and its products and services. The team's communication assets, along with financing and aggrandizing the sport's spectacle, can be a social assurance tool for the teams' identities as a way of boosting the consumption process.

KEYWORDS: KEYWORDS • SPORT • COMMUNICATION • SOCCER • CONSUMPTION • ADVERTISING

Resumen

Los clubes de fútbol, además de la función de generar una identidad común, son capaces de desarrollar un fuerte poder aglutinador sobre las personas, que pueden expresar el sentimiento de pertenencia a este grupo por medio del consumo simbólico del club y/o sus productos y servicios. La comunicación, además de financiar y agrandar el espectáculo deportivo, constituye una herramienta de ratificación de la identidad de cada club, como forma de potencializar el proceso de consumo.

PALABRAS CLAVE: DEPORTE • COMUNICACIÓN • FÚTBOL • CONSUMO • PUBLICIDAD 
Este artigo busca observar e avaliar os clubes de futebol como motivadores e Einfluenciadores sociais e culturais no contexto brasileiro, verificando o papel da comunicação nesse processo de produção simbólica e de consumo, para o que se faz também uma analise de caso.

Compartilhando de uma definição de Nelson Rodrigues (apud Franco Júnior, 2007, p. 210), de que "não se trata de uma paixão, mas de uma senha para a cidadania", temos como hipótese primária o fato de que, possivelmente, os clubes de futebol exerçam função de estratos sociais, apresentando autonomia em relação à sociedade externa, assim como apresentam identidades e comportamentos coletivos. Nesse cenário, muitas vezes, o indivíduo-torcedor pode se tornar estrutura e estruturante de uma massa única (torcida), cabendo a ele a possibilidade de absorção dos valores e da identidade coletiva. Uma segunda hipótese infere que o consumo de produtos (ou serviços) relacionados ao clube pode ser uma manifestação do comportamento/ consciente coletivo, além de elemento de inserção e de demonstração de pertencimento ao grupo.

\section{UM ESPETÁCULO RETROALIMENTADO PELA COMUNICAÇÃO}

É notório e importa ressaltar que o futebol deixou de ser apenas um esporte lúdico e um território exclusivamente dominado pela paixão. Hoje ele movimenta grandes montantes financeiros, por meio de patrocínios e de "venda" de jogadores (fontes oriundas de dentro do campo), além do licenciamento de produtos e de outras formas mais (graças à torcida). Os meios de comunicação, além de colaborarem para tornar o esporte um espetáculo, também o financiam, por meio de patrocínios, direitos de transmissão, inserções publicitárias etc.

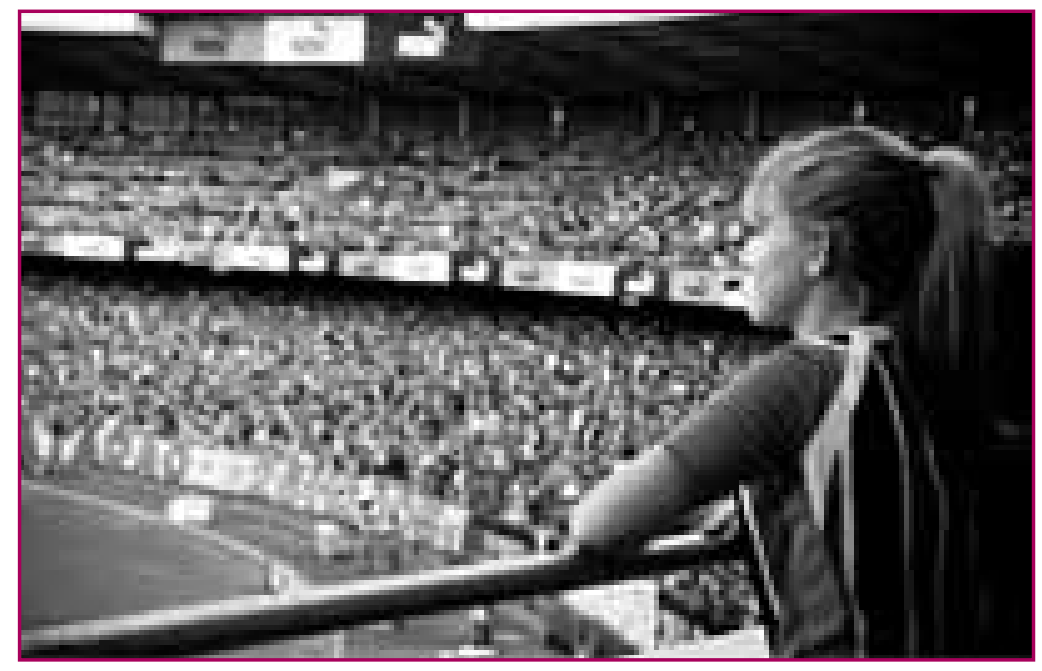

A espetacularização e capitalização do esporte (Foto de Eneas de Troya) 
A importância que o futebol adquiriu na sociedade contemporânea é digna de destaque. No Brasil, sua quase onipresença faz com que ele seja praticado, assistido e discutido em todas as classes e todos os campos sociais. Segundo DaMatta (2010, p. 41), 64\% de toda a população brasileira têm algum time de futebol e, destes que alegam torcer, $82 \%$ acompanham o time diariamente pela mídia. Mas nem sempre foi assim. Se hoje o futebol tem tamanha abrangência, os meios de comunicação de massa tiveram (e ainda têm) papel fundamental, pois, ao mesmo tempo em que garantem o acesso fácil à informação esportiva, também a hiperbolizam e ratificam seu caráter espetacular.

A educação dos gostos é o ponto-chave na constituição de um mercado. Nesse caso, o início da imprensa esportiva foi fundamental para educar o público com novas regras, práticas e para construir os ídolos locais que realimentam toda a indústria (Soares; Vaz, 2009, p. 501).

A publicidade também possui papel essencial no processo de produção simbólica do futebol, já que, em sua essência mais primitiva, ela objetiva a venda e faz dos veículos um meio para atingir esse objetivo. No entanto, antes de se tornarem agentes de consumo, os veículos precisavam ser objetos de consumo. Dessa forma, à medida que o futebol se tornara fonte de audiência cativa, a publicidade ao mesmo tempo exigia e garantia a profissionalização do rádio (e dos veículos de comunicação em geral), assegurando a existência de recursos que melhorariam a transmissão do espetáculo e que, consequentemente, mobilizariam ainda mais pessoas. O futebol, portanto, fora retroalimentado pela publicidade num ciclo vicioso e virtuoso.

Essa criação de valor passa, por exemplo, pela potencialização da torcida, antes limitada aos torcedores do estádio, quando as tevês passaram a massificar a transmissão do evento. (...) Com isso, é incorporado o telespectador, o torcedor da poltrona. Outra constatação desse processo (...) foi o potencial propagandístico dos times de futebol, o que deu início a patrocínios a clubes, jogadores e anúncios em estádios (Gurgel, 2006, p 43).

Por meio desse processo, de conseguir se vender e também ser agente de promoção do consumo de bens concretos e simbólicos que veicula, a mídia adota estratégias que tornam superlativas algumas características de seus objetos de observação, o que cria um processo de espetacularização da (hiper)realidade, na qual é incentivado o seu consumo para suprir essa necessidade artificialmente produzida.

Mecanismos psicológicos de identificação com os ídolos esportivos, por meio das imagens vencedoras que são construídas pela mídia, ajudam a criar necessidades de consumo no imaginário dos torcedores, que para satisfazê-las procuram comportar-se como seus ídolos, adquirir os produtos e os símbolos a eles relacionados, enfim, "assumem" os valores que eles ajudam a difundir (Pires, 2007, p. 2). 


\section{A FERRAMENTA SOCIAL FUTEBOLÍSTICA}

A partir deste ponto, tomaremos o conceito de campo social, de Pierre Bourdieu, como fonte teórica para discussão sobre a união formada entre os torcedores de um clube, união que se assemelha com a formação de pequenas sociedades, tendo como característica principal o fato de se justificarem por um clube de futebol.

Segundo Bourdieu (1983), o campo social pode ser entendido como o agrupamento de pessoas (ou "agentes", segundo o autor), física ou psicologicamente, os quais são orientados por alguma característica em comum e que possam apresentar relativa autonomia em relação à sociedade externa. Podemos considerar como campo social, por exemplo, os "vizinhos da rua", o "sindicato dos metalúrgicos", a "associação de hippies" etc., possuindo cada campo laços específicos entre seus membros.

Podemos aqui inferir que as torcidas de futebol exercem o papel de campo social, no qual as pessoas se aglutinam em virtude de um objeto comum: os signos do time do coração. Tais signos são, ao mesmo tempo, objetos de adoração do campo (o escudo, as cores do time etc.), como também elementos diferenciadores e ratificadores do campo (linguagem, identidade e comportamentos coletivos únicos e diferentes de campos e ambientes externos).

"Esses grupos sociais permitem predizer as outras propriedades e distinguem e agrupam os agentes que mais se pareçam entre si e que sejam tão diferentes quanto possível dos integrantes de outras classes, vizinhas ou distantes" (Bourdieu, 1996, p. 24). Escolher um clube, e consequentemente uma torcida (campo social), acarreta necessariamente a negação dos demais grupos sociais (as demais torcidas).

“Torcer por um clube gera o sentimento de pertencer a uma grande família anônima, que o indivíduo escolheu por razões variáveis, não é a família nacional que lhe foi imposta pelo destino" (Franco, 2007, p. 206). Podemos concluir, portanto, que um dos principais motivadores para a união coletiva em torno de um clube é o sentimento de pertencimento a um campo social pequeno e não mandatório, dando ao indivíduo a sensação de escolha e, consequentemente, de identidade e representação.

É nele, portanto [o campo social], onde seus integrantes aprendem a reconhecer o certo e o errado, mas não só, também a se definir, a forjar um discurso comum de pertencimento, a identificar os traços de uma identidade integradora, a dar a ver a fronteira simbólica que aparta o dentro e o fora. (Barros Filho; Lopes, 2006, p. 45).

Em um país como o Brasil, onde $64 \%$ da população declara torcer por algum clube (DaMatta, 2010), não podemos negar o papel massificador e domina- 
dor do esporte enquanto traço cultural. Podemos dizer, por exemplo, que um indivíduo que afirma não ser torcedor de qualquer clube está sujeito a certo estranhamento diante dos outros e, em alguns casos, tal estranhamento pode gerar preconceito e exclusão social. Daí decorre a conclusão de que o futebol pode, sim, ter papel de dominação cultural.

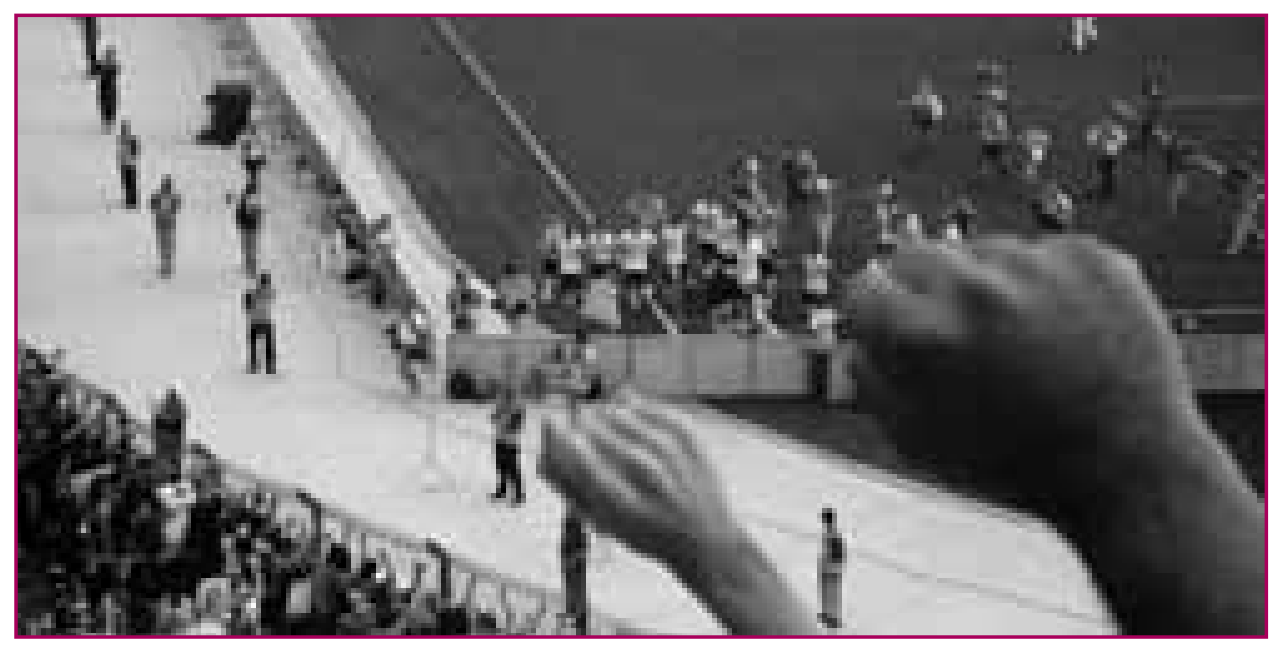

Troca simbólica entre torcedor e clube (Foto de João G. Fernandes)

Podemos associar tal ação dominante do esporte com o conceito de habitus, defendido por Bourdieu e, com isso, traçar algumas hipóteses para o processo de escolha e de aceitação de um clube como elemento pessoal. Segundo Bourdieu (1996), o habitus é uma relação cultural estabelecida entre o agente e a sociedade, sendo o agente ao mesmo tempo dominado e ratificador da cultura vigente. Ou seja, os elementos circundantes da sociedade na qual o agente está inserido praticamente o dominam e o obrigam a aceitar tais elementos culturais (a "escolha obrigatória" de um time de futebol, por exemplo). Por outro lado, o agente também exerce papel de ratificador da cultura dominante à medida que a aceita, tornando-a mais forte.

O habitus pode ser compreendido como a conexão entre o ator social e a sociedade, uma segunda natureza. Trata-se, portanto, de situar o fenômeno em uma lógica onde os indivíduos são matizados pela cultura, mas, ao mesmo tempo, tendo suas práticas como parte estruturante dessa. Portanto, há uma estruturação que se estabelece na prática; as relações de dominação se fazem, desfazem e se refazem na e pela interação entre as pessoas (Bourdieu, 1996, p. 184).

Além disso, com base na afirmação de Bourdieu (1983), nem sempre as vitórias e as conquistas clubísticas podem ser consideradas como troféu social 
máximo para o campo. Muitas vezes, o reconhecimento e fortalecimento do clã, em detrimento dos clãs rivais, é muito mais preponderante. Tal fortalecimento do campo social pode, sim, vir por meio do desempenho esportivo, uma vez que ratifica sua superioridade; mas não de forma intrínseca.

A lógica de todo clube, como toda sociedade, é seu reconhecimento por parte dos congêneres, é a afirmação e difusão de seu poder. As vitórias esportivas, em certo sentido, não são objetivos últimos, mas instrumentos privilegiados para o fortalecimento clânico (Franco Júnior, 2007, p. 207).

Para Bourdieu (1996), o campo social é estruturado e estruturante por formas particulares de ilusão, fazendo com que a importância de se envolver não seja calculada, mas implícita. A esse reconhecimento prévio dos troféus e da obviedade das razões que circundam a validade de compor certa atividade social denomina-se illusio.

A illusio (...) é estar envolvido, é investir nos alvos que existem em certo jogo, por efeito da concorrência, e que apenas existem para as pessoas que, presas ao jogo, e tendo as disposições para reconhecer os alvos que aí estão em jogo, estão prontas a morrer pelos alvos que, inversamente, parecem desprovidos de interesse do ponto de vista daquele que não está preso a este jogo, e que o deixa indiferente (Bourdieu, 1996, p. 152).

O reconhecimento e o investimento nos alvos específicos do jogo social (engajamento não calculado em prol dos benefícios do campo social) decorre, portanto, da atribuição de valor a algum objeto de luta, definido em um processo de socialização estabelecido, quase sempre, dentro do próprio campo social. "Admitir o valor do troféu é condição de pertencimento ao campo" (Barros Filho; Lopes, 2006, p. 60).

No caso específico dos clubes de futebol, podemos inferir que o ato de torcer pode ser interpretado (por meio de uma ilusão coletiva) como uma ferramenta para a obtenção dos troféus e objetos de luta do campo social, os quais (apesar de subjetivos e não mandatórios) normalmente estão relacionados ao desempenho esportivo da equipe. Ou seja, o indivíduo é envolvido por uma ilusão coletiva incontestável (a necessidade de torcer), na qual o reconhecimento do valor do troféu social (normalmente as vitórias esportivas) é a condição de pertencimento ao grupo, pois, afinal, a razão mais simplista que explica a aglutinação de indivíduos em uma única torcida é o simples ato de "torcer" pela mesma coisa.

Podemos inferir, portanto, que a illusio aplicada ao contexto do futebol se manifesta como a ilusão coletiva incontestável que rege a necessidade de torcer pelo seu clube, como forma de buscar os troféus do campo social. O desejo incontestável de torcer pelo clube (illusio) é o elemento ratificador de pertencimento ao grupo (torcida). 
Partindo desse princípio, de que para participar (do grupo e do espetáculo) é necessário torcer, assistir aos jogos do time é condição básica para isso. No entanto, o número de pessoas que assistem a seu time do lado de dentro do estádio é infinitamente menor que o número de indivíduos que o acompanham graças aos meios de comunicação. Segundo Damatta (2010, p. 44), 99\% dos torcedores não foram ao estádio nenhuma vez nos últimos dois anos . O consumo simbólico do clube, por meio dos veículos de comunicação, é uma das formas mais notáveis de participação e de inserção no grupo. Tal processo é tão importante para a manutenção do sistema esportivo espetacular que a maior fonte de renda dos clubes brasileiros está na venda dos direitos de imagem, para as emissoras de televisão, as quais representam $28 \%$ do total ${ }^{1}$.

Torcer por um clube é se identificar com suas vitórias, que completam ou substituem as vitórias pessoais do indivíduo. Daí decorre o uso frequente da camisa do clube depois de uma vitória importante ou do sucesso do time em alguma competição. O uso do produto representa, ao mesmo tempo, a ratificação do pertencimento do indivíduo ao grupo e a troca de valores psicológicos entre ambos. Consumir um produto do clube, portanto, pode assumir a função de identificação grupal e dos valores coletivos. "Usar a camisa de seu time implica demonstrar sua predileção, sua tribo e, ao mesmo tempo, negar e agredir simbolicamente as outras tribos, os outros times" (Morato, 2005, p. 81).

Por fim, podemos inferir que, além de os clubes possuírem forte poder de atração social sobre os torcedores, o consumo - simbólico e de produtos - dessas agremiações se torna o fator ratificador e condição básica, de pertencimento e de representação identitária dos valores clubísticos.

\section{A TORCIDA QUE SE FEZ "REPÚBLICA"}

Em $1^{\circ}$ de setembro de 2010 o Sport Club Corinthians Paulista completou seu centésimo aniversário. Mais do que uma simples data de fundação, o centenário corintiano representava uma celebração coletiva para um grupo composto por mais de 30 milhões de pessoas.

Havia ali uma grande oportunidade de mobilizar um número imenso de pessoas, algumas já com grande envolvimento emocional com o objeto em questão. Nesse contexto, Corinthians e Nike (patrocinadora e fornecedora oficial de material esportivo do clube) lançaram a campanha da "República Popular do Corinthians".

Tomaremos, a partir deste ponto, duas referências teóricas como base para a discussão, cujo objetivo é ilustrar, por meio da análise deste caso real, os conceitos já apresentados. O primeiro conceito é o da "escada rolante", apre-

1 Auditoria BDO RCS. In: site GloboEsporte.com, 13/05/2011. 
sentada por Mullin (2004); já o segundo é o da divisão dos jogos elaborada por Caillois (1990), a qual demonstra um aporte interessante para abordar a componente lúdica dos jogos na cultura.

A "escada rolante" nada mais é que uma representação gráfica do envolvimento do consumidor esportivo, a qual, além de fazer a segmentação dos consumidores em degraus, também demonstra as motivações que permeiam o movimento de ascensão em cada nível da escada. Os degraus próximos ao chão abrigam os consumidores com baixo envolvimento esportivo, cujo desembolso financeiro com o esporte também é (empiricamente) muito pequeno; enquanto que os consumidores dos níveis mais elevados apresentam grande envolvimento e despendem grande somas financeiras com artigos esportivos.

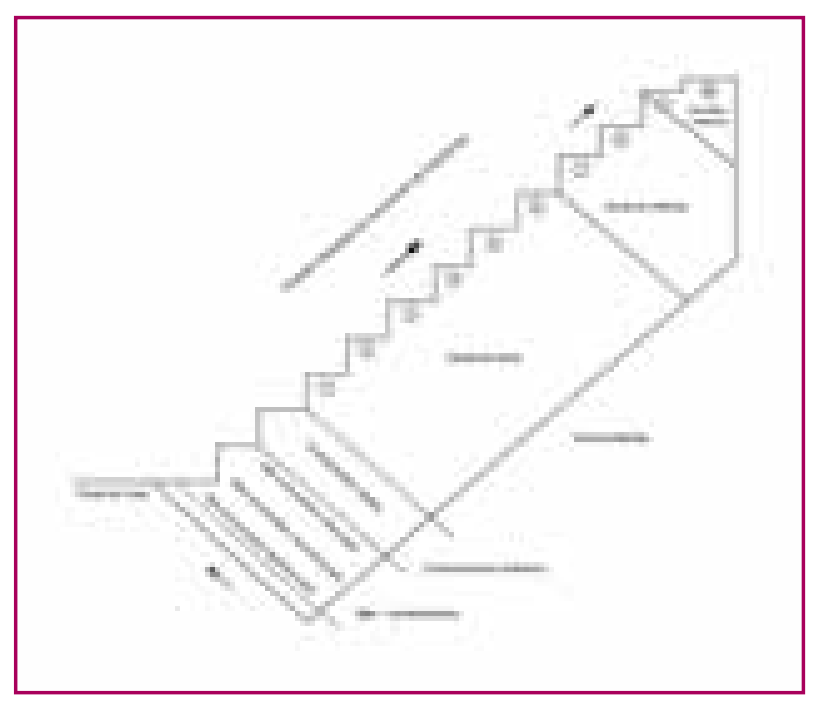

Escada rolante de Mullin

Por meio desse esquema, torna-se claro que os torcedores podem aumentar seu grau de relacionamento com o clube (como no movimento de uma escada rolante), estando o envolvimento emocional diretamente relacionado à propensão de consumo. A campanha analisada a seguir, por meio dos mais diversos canais de comunicação, construiu uma narrativa discursiva objetivando aumentar o envolvimento emocional daqueles que já possuíam alguma afinidade com o clube e que despenderiam maior energia e recursos financeiros com o mesmo.

É justamente a partir da análise da construção da narrativa discursiva que podemos aplicar a divisão dos jogos (como modo de representação, percepção e interação lúdica da sociedade), apresentados pelo sociólogo e antropólogo 
Roger Caillois (1990), o qual classifica os jogos em quatro categorias básicas: agôn, os jogos de competição; alea, os jogos de azar; mimicry, os jogos de representação, e ilix, os jogos de vertigem.

A campanha da "República Popular do Corinthians" partia da premissa criativa de que os corintianos formavam uma verdadeira nação, na qual os mais de 30 milhões de torcedores possuíam hábitos, costumes, linguagem e comportamentos próprios. Tudo isso não apenas estabelecia laços de mais um campo social, mas os diferenciava do restante das pessoas a ponto de poderem ser reconhecidos como uma microssociedade forte, unida e única.

A solução criativa foi a criação de um factóide, a "República Popular do Corinthians", a qual seria reconhecida como um estado-nação. Os torcedores seriam o povo que formavam a república, enquanto os jogadores seriam os heróis que ilustram a história da nação.

Para gerar cobertura da campanha, a estratégia de lançamento contou com o uso de canais de comunicação de massa (como televisão e mídia impressa), aliado a canais segmentados e de grande afinidade com o público (sites especializados, comunidades nas redes sociais e mídia impressa esportiva). Além do mais, o lançamento foi feito em um evento público, com a presença de todos os jogadores do elenco, funcionando como chamariz para a presença espontânea da mídia esportiva, garantindo a cobertura inicial da campanha.

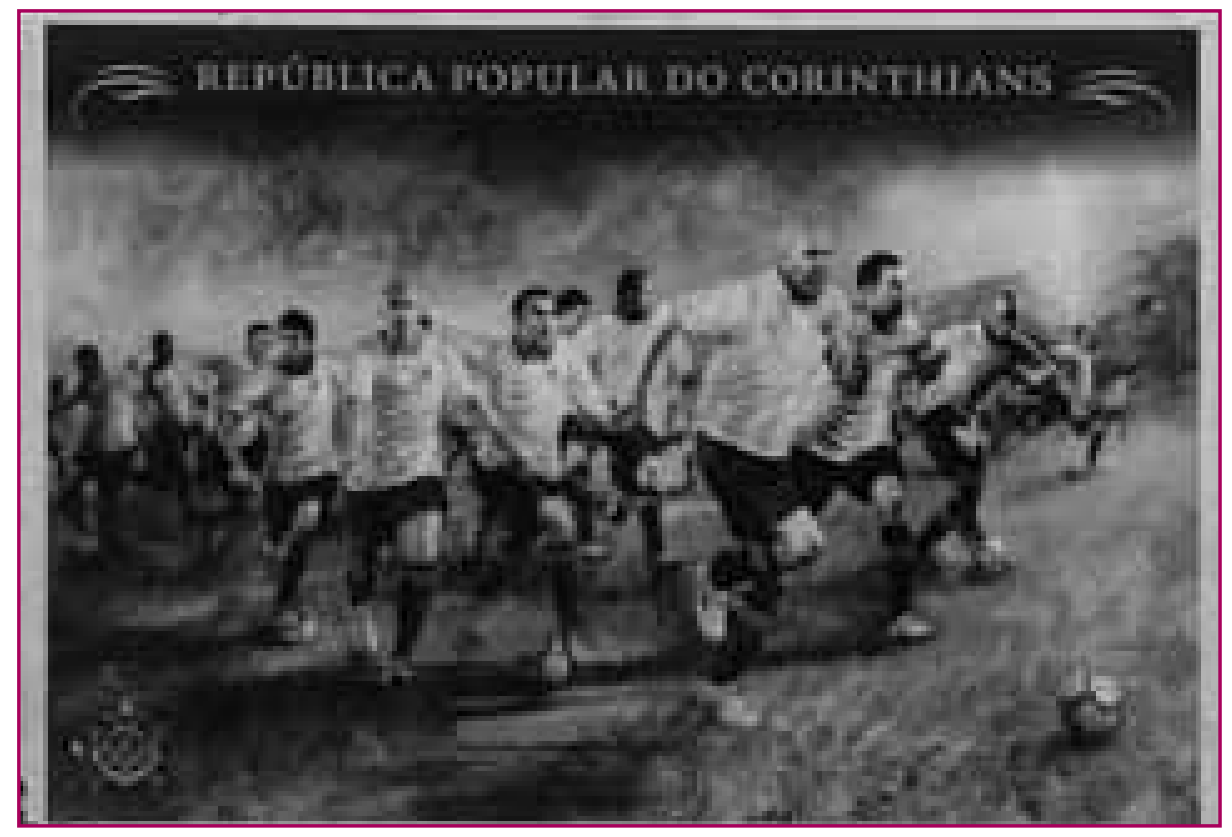

Anúncio publicitário da campanha 
O grande destaque dessa campanha foi a tangibilização do discurso, que tornou ainda mais realista o factóide da "república corintihiana". A Nike desenvolveu a maioria dos elementos necessários para um "país" ser reconhecido como tal, disponibilizando esse tipo de conteúdo e o deixando sob o poder de personalização dos consumidores/torcedores.

As pessoas podiam, por exemplo, emitir uma série de documentos, que remetiam às práticas de um verdadeiro país, os quais poderiam ser obtidos no site ou na página do Facebook da campanha. Era possível emitir carteira de identidade, certidão de nascimento e passaporte. Além desses, havia ainda outros documentos: a carta magna da república, que demonstrava a legislação da nação e fora veiculada nos maiores jornais do país; a carta de anistia, que podia ser enviada para amigos não-corintianos; a moeda própria, o "corinthio", emitido pelo "Ministério da Fazendinha"2 e que podia ser usado como descontos nas lojas do clube; por fim, também havia uma embaixada itinerante, que funcionava como exposição da campanha e venda de produtos.

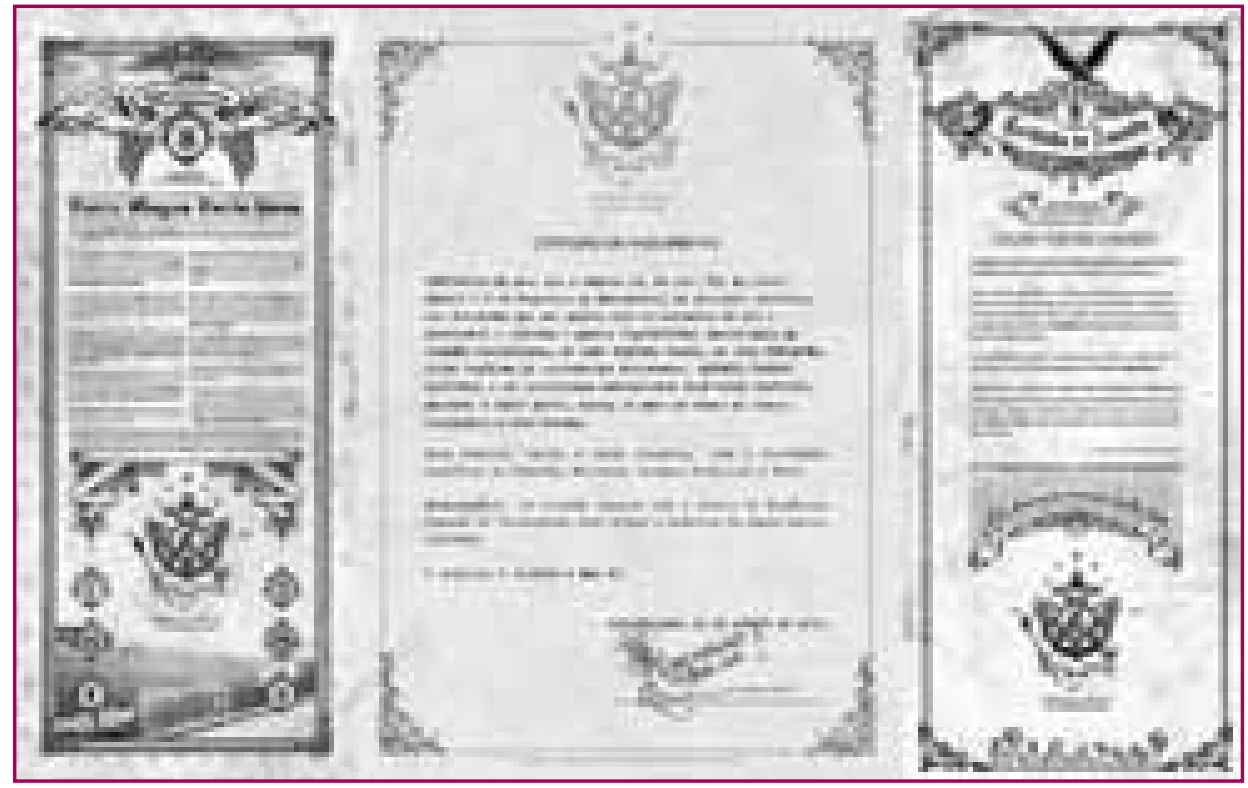

Carta magna, certidão de nascimento, carta de anistia

A Nike usou outro canal de comunicação, praticamente exclusivo no contexto futebolístico: o bandeirão do estádio. Rotulado como "uma das maiores bandeiras de um país do mundo”, com 2,7 mil metros quadrados e que precisava

2 Alusão ao antigo estádio do Corinthians, chamado de "Fazendinha", e ao Ministério da Fazenda. 
da ação de mais de 10 mil torcedores para ser "hasteado", ele foi usado em todos os jogos do ano, o que gerou ainda mais mídia espontânea.

Além disso tudo, em outro evento público, houve a posse simbólica do primeiro "presidente" da "República Popular do Corinthians", Luís Inácio Lula da Silva, então presidente do Brasil (e corintiano declarado), que contava com $82 \%$ de aprovação popular na época ${ }^{3}$.

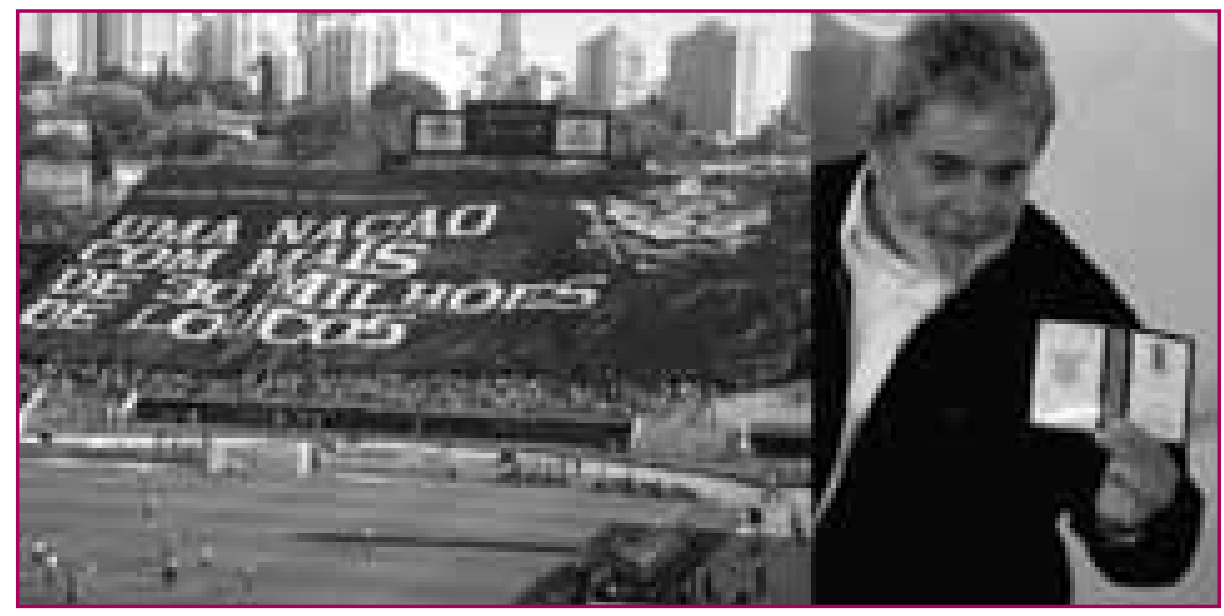

Bandeirão da "república" e seu primeiro "presidente", Lula

Importa ressaltar que um dos grandes destaques da "República Popular do Corinthians" estava na construção da narrativa discursiva que, segundo os preceitos de Caillois (1990), se enquadra como manifestação dos jogos mimicry (os jogos de representação).

Podemos considerar que essa campanha usou elementos narrativos dos jogos mimicry porque apresentava, claramente, a representação de um "faz de conta", criando outra realidade, uma realidade projetada (a tal "república") que é diferente da realidade real. Segundo a definição de Caillois (1990, p. 39), “o jogo pode consistir não na realização de uma atividade ou na assunção de um destino num lugar fictício, mas sobretudo na encarnação de um personagem ilusório e na adoção do respectivo comportamento”.

De fato, o clube assumiu o comportamento de outro personagem (um país), indo além do discurso por meio da emissão de pseudodocumentos e outras atitudes. Aos jogadores coube também atenção especial na narrativa publicitária, a qual os transvestiu em personagens heróicos. Por fim, à torcida também

3 CNT/Sensus In: site do Estadão, 21/05/2011. 
foi dado um personagem, o de população nacional, cabendo a ela se envolver e se comportar como tal.

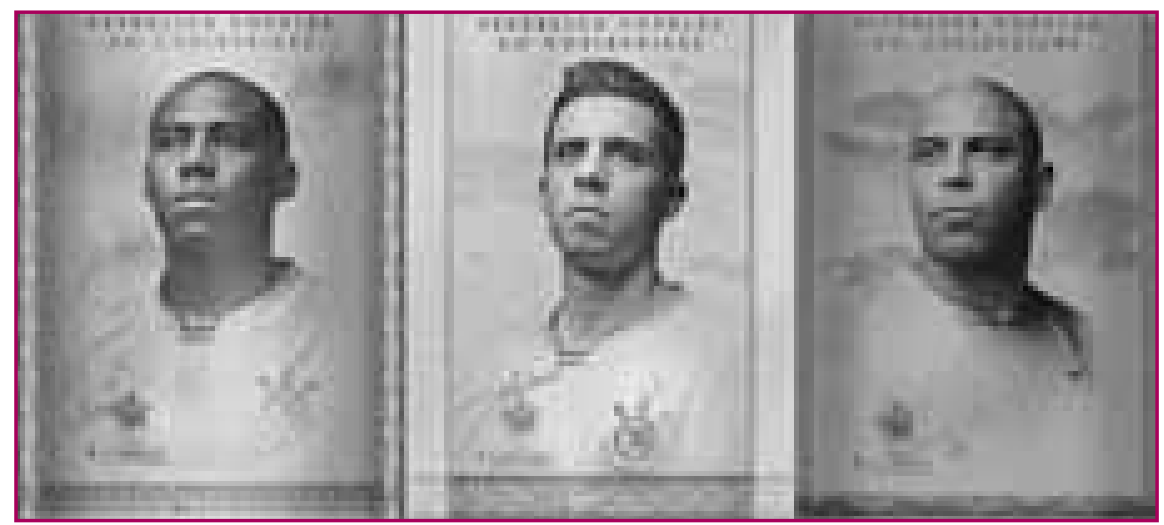

Construção imagética heróica dos jogadores

Caillois (1990) admite que, para a realidade projetada não ser considerada incongruente e, portanto, para ser aceita (mesmo que temporariamente), ela carece de alguns elementos que a aproximem da realidade real. No caso da "República Popular do Corinthians", a realidade projetada é construída graças ao exagero e à dramatização de elementos reais. A quantidade de torcedores, próxima de 34 milhões, segundo Corinthians (2008, p. 9), por exemplo, é um dado empírico; já a noção de república remete à ideia comumente usada de "nação corintiana", inclusive, a Gaviões da Fiel (maior torcida organizada do Corinthians) possui e divulga seus próprios valores sociais: lealdade, humildade e procedimento.

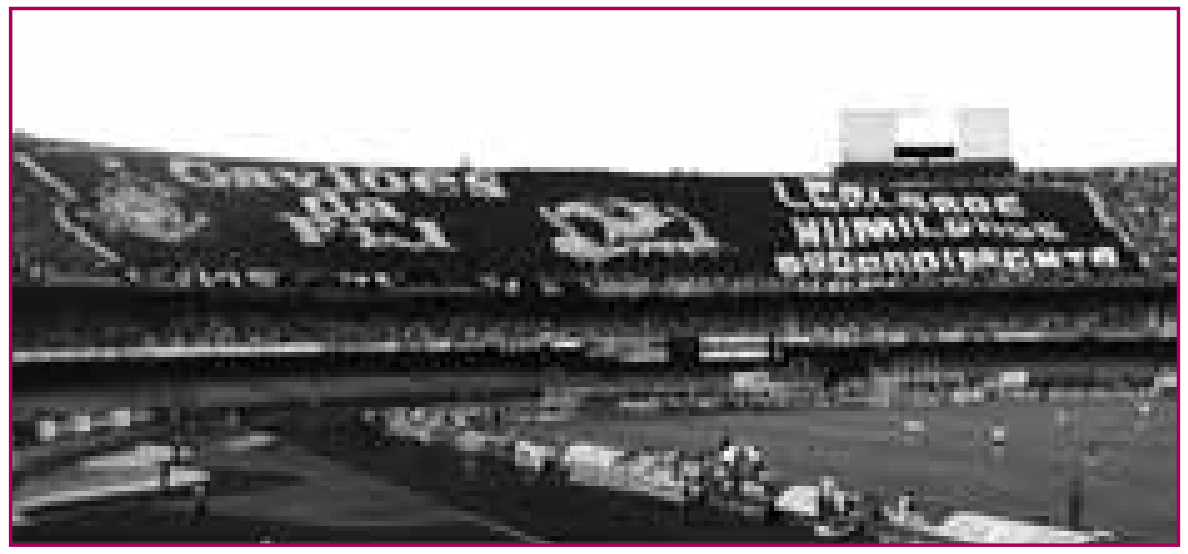

Valores da torcida corintiana 
Além do mais, considerando a importância do futebol nacionalmente, "é natural a reverência de que são objeto seus principais personagens, os jogadores, alguns comparados a deuses" (Franco, 2007, p. 259). A comunicação publicitária apenas hiperbolizou a realidade, o que torna crível a narrativa, além de gerar identificação das pessoas. Sobre isso Goffman (apud Gastaldo, 2002, p. 93) diz:

Os anúncios publicitários realizam uma representação (especialmente no sentido de "dramatização") de cenas consideradas "cotidianas", na qual se constrói uma espécie de "hiper-ritualização" dessa vida cotidiana. A aproximação do anúncio com a noção de ritual deve-se à semelhança estrutural entre ambos. Tanto o ritual, quanto o anúncio publicitário (...) recorrem a tipificações socialmente aprovadas e a uma gestualidade que se refere àquilo que deve ser tomado como uma resposta interior.

Caillois (1990) admitiu, até mesmo, ser possível que a realidade projetada possa ser interpretada como mais verdadeira do que aquela vista diante dos olhos (a realidade real). O motivo é que a imagem projetada pode já estar presente no âmago do indivíduo e / ou da sociedade, de forma inconsciente e talvez até enrustida, cabendo a algum estímulo externo (comunicação) a tarefa de despertá-la.

Importante ressaltar que, nesse caso, a narrativa publicitária da campanha buscou criar a sensação de que a realidade projetada pudesse ser "mais real do o real", de forma que todos os 30 milhões de torcedores se sentissem representados e não impactados por ela. Tanto que dificilmente os dirigentes e jogadores do clube se referiam à campanha como "propaganda" ou "ação de marketing"; ela era tratada como identidade definitiva do clube.

Podemos inferir que tal sentimento de representatividade e de pertencimento a um campo social clubístico, com características e personalidade coletivas próprias (tacitamente ratificadas pela comunicação), obtém como consequência o aumento do envolvimento do torcedor com o clube e a ascensão do mesmo na escada rolante de envolvimento e consumo proposta por Mullin.

Além disso, o uso de produtos/serviços do clube pode assumir o papel de um dos mecanismos de entrada no grupo e sinal de pertencimento. "O discurso publicitário incorpora elementos rituais, narrativos, icônicos (...) para compor, em uma grande bricolagem, um discurso sobre a sociedade na qual o produto e seu valor se inserem de modo inequívoco” (Gastaldo, 2002, p. 80).

Sobre os resultados, um adendo importante é que, durante a construção do presente artigo, a campanha ainda permanecia ativa, o que dificulta a apresentação de dados completamente conclusivos sobre o desempenho geral da campanha. Mas, no que tange resultados diretos ${ }^{4}$, a campanha repercutiu de tal forma nos meios de comunicação que chegou a alcançar o valor de R 13

4 Nike. In: Youtube, 09/05/2011. 
milhões em mídia espontânea, mais de 1 milhão de carteiras de identidade foram emitidas somente no primeiro mês, além de 230 mil pessoas terem concluído seu cadastro no site, formando um importante mailing para a Nike.

A venda de produtos, diretamente relacionados com a campanha, foi de R\$ 8,6 milhões (em apenas seis meses). Todavia, a análise de resultados baseada unicamente na venda de produtos pode se tornar um pouco superficial, à medida que o aumento do nível de envolvimento da torcida com o clube (de valor imensurável) culmina em consequências financeiras em toda a cadeia de produção do clube.

Podemos considerar, portanto, que a campanha publicitária foi um dos fatores que influenciou a alteração positiva de outras métricas do clube, no período entre 2009 e 2010 . O aumento do faturamento de bilheteria, por exemplo, passou de $\mathrm{R} \$ 27,6$ milhões para $\mathrm{R} \$ 29,4$ milhões, enquanto que os direitos de transmissão de imagem saltaram de R\$ 29 milhões para R $\$ 55$ milhões. $\mathrm{O}$ faturamento total do clube sofreu variação positiva de $17 \% \mathrm{em}$ relação ao ano anterior ${ }^{5}$.

A campanha fez tamanho sucesso que a Nike pretende usá-la como plataforma permanente de contato com os consumidores corintianos, além de expandir a estratégia de comunicação para times de outros países.

\section{CONSIDERAÇÕES FINAIS}

"É dito com frequência que o mercado de consumo seduz os consumidores. Mas para fazê-lo ele precisa de consumidores que queiram ser seduzidos" (Bauman, 1999, p. 92).

Hoje, é sabido que o futebol movimenta mundialmente cerca de US\$ 210 bilhões ao ano (Gurgel, 2006). Devemos ressaltar a importância da comunicação (sobretudo a propaganda), tanto na manutenção como na capitalização do espetáculo esportivo. Hoje, as duas maiores fontes de receitas dos clubes estão, de alguma forma, relacionadas ao processo de comunicação midiática: as cotas de televisão, 28\%; e os patrocínios / publicidade, 17\% (DaMatta, 2010). As venda das cotas de televisão ratifica o quanto o esporte se tornou um espetáculo por si só, trazendo audiência e anunciantes à transmissão. Além da movimentação financeira no Brasil, de aproximadamente US\$ 7 bilhões ao ano (Gurgel, 2006), devemos ressaltar o contexto sociocultural no qual o esporte está envolvido. O futebol no Brasil está enraizado na cultura, fazendo parte da identidade nacional e individual. É um fato que também foi potencializado e hoje estruturado graças à influência dos meios de comunicação, seja por meio do jornalismo, das relações públicas ou da propaganda.

5 Auditoria BDO RCS. In: site GloboEsporte.com, 21/05/2011. 
A aglutinação coletiva em torno de um clube de futebol pode, portanto, assumir o papel de um campo social estruturado e autônomo, uma vez que a torcida se organiza (primariamente) ao redor do mesmo conjunto simbólico (os signos do clube). Além disso, é dentro desse campo que surgem as "normas de ação" diferentes da sociedade exterior e, por fim, as torcidas constroem sua identidade coletiva própria, a qual (dependendo do contexto) pode se sobrepor à identidade e personalidade individual.

Além disso, podemos inferir que os clubes exercem forte poder de atração social e psicológica sobre os indivíduos, cuja motivação principal é o desejo de diferenciação social por meio de um grupo que, de certa forma, os represente. Com isso, há o forte sentimento de pertencimento, que precisa ser representado de alguma forma.

Com base nos preceitos de Morato (2005) e de Bourdieu (1996) podemos inferir que o sentimento de pertencimento pode ser canalizado, principalmente, por duas formas básicas: 1) o consumo direto de produtos relacionados ao clube; e 2) a ilusão da inquestionabilidade do ato de torcer (que também possui reflexos no consumo, sobretudo midiático).

O torcedor que usa um produto do clube, normalmente a camisa - $(84 \%$ das vendas, segundo DaMatta (2010) -, o faz porque com isso ratifica tanto seu pertencimento ao campo social clubistico, como também evidencia os valores e a personalidade coletiva com a qual compactua. Por outro lado, a maior representação comportamental do sentimento de pertencimento se dá pelo "ato de torcer". Bourdieu (1996) classifica como illusio o fato de, para pertencer ao grupo, alguns padrões psicológicos e comportamentais serem tidos como óbvios e, por isso, inquestionáveis. $\mathrm{O}$ ato de torcer é, por essência, algo inquestionável, que credencia o indivíduo como pertencente àquele grupo e o envolve no consumo simbólico do clube.

Por fim, é importante ressaltar que, na campanha analisada, "República Popular do Corinthians”, houve a exaltação de elementos e valores coletivos já existentes. À comunicação coube apenas o papel de hiperbolizar tais valores, além de inserir o consumidor (torcedor) como protagonista na narrativa construída. Trata-se de um fato que foi essencial para o sucesso da mesma em todos os níveis: comunicacional, social e comercial.

\section{REFERÊNCIAS}

BAUMAN, Zygmunt Globalização: as consequências humanas. Rio de Janeiro: Jorge Zahar, 1999.

BARROS FILHO, Clóvis de; LOPES, Felipe T. Paes As regras da publicidade: do aluno ao profissional. Revista Interamericana de Comunicação Midiática, UFSM, v. 5, n. 1, p. 45, 2006. Disponível em: <http://goo.gl/MRTiP>.

BOURDIEU, Pierre. Questões de sociologia. Rio de Janeiro: Marco Zero, 1983. 
BOURDIEU, Pierre. Razões práticas da teoria da ação. Campinas: Papirus, 1996.

CAILLOIS, Roger. Os jogos e os homens: a máscara e a vertigem. Lisboa: Cotovia, 1990.

CORINTHIANS Sport Club. Relatório de sustentabilidade. São Paulo,2008. Disponível em: <http://goo.gl/sqgaF>.

DaMATTA, Roberto et al. (Org.). Lance imperdível!: um retrato do esporte no Brasil. Rio de Janeiro: Lance!, 2010.

ESTADÃO Recorde de aprovação a Lula é mundial, diz CNT/Sensus. 21/05/2011. Disponível em: <http://goo.gl/hRPmn>. AcesSo em: 21 maio 2011.

FRANCO JÚNIOR, Hilário. $A$ dança dos deuses: futebol, sociedade e cultura. São Paulo: Companhia das Letras, 2007.

GASTALDO, Édison. Pátria, chuteiras e propaganda: o brasileiro na Copa do Mundo. São Paulo: Annablume; São Leopoldo, RS: Ed. Unisinos, 2002.

GLOBOESPORTE.COM. Clubes brasileiros vendem menos e arrecadam mais com patrocínios. 21/05/2011. Disponível em: $<$ http://goo.gl/fbtAw>. Acesso em: 21 maio 2011.

GURGEL, Anderson. Futebol S/A: a economia em campo. São Paulo: Saraiva, 2006.

MORATO, Márcio P. A dinâmica da rivalidade entre pontepretanos e bugrinos. In: DAOLIO, Jocimar (Org). Futebol, cultura e sociedade. Campinas: Autores Associados, 2005. p. 73-104.

MULLIN, Bernard J. et al. (Org.). Marketing esportivo. Porto Alegre: Artmed / Bookman, 2004.

PIRES, Giovanni de Lorenzi. 0 esporte e os meios de comunicação de massa: relações de parceria e tensão. Possibilidades de superação? In: GRUNENNVALDT, José Tarcísio et al. (Org.). Educação física, esporte e sociedade: temas emergentes. São Cristóvão, SE: DEF/UFS, 2007.

SOARES, Antonio Jorge; VAZ, Alexandre Fernandes. Esporte, globalização e negócios: o Brasil dos dias de hoje. In: DEL PRIORE, Mary; MELO, Victor A. (Org). História do esporte no Brasil. São Paulo: Unesp, 2009.

WISNIK, José Miguel. Veneno remédio: o futebol e o Brasil. São Paulo: Companhia das Letras, 2008.

YOUTUBE, 09/05/2011. Nike: República Popular do Corinthians. Disponível em: <http://goo.gl/9fDRm>. Acesso em: 09 maio 2011.

Recebido em: 31.08.2011 / Aceito em: 21.10.2011 